\title{
Adsorption of pharmaceuticals from aqueous solutions using biochar derived from cotton gin waste and guayule bagasse
}

\author{
Marlene C. Ndoun ${ }^{1}\left[\right.$ D $\cdot$ Herschel A. Elliott ${ }^{1} \cdot$ Heather E. Preisendanz ${ }^{1} \cdot$ Clinton F. Williams $^{2} \cdot$ Allan Knopf $^{2}$. \\ John E. Watson ${ }^{3}$
}

Received: 10 March 2020 / Accepted: 1 October 2020 / Published online: 16 November 2020

(c) The Author(s) 2020

\begin{abstract}
Biochars produced from cotton gin waste (CG) and guayule bagasse (GB) were characterized and explored as potential adsorbents for the removal of pharmaceuticals (sulfapyridine-SPY, docusate-DCT and erythromycin-ETM) from aqueous solution. An increase in biochar pyrolysis temperature from $350{ }^{\circ} \mathrm{C}$ to $700{ }^{\circ} \mathrm{C}$ led to an increase in $\mathrm{pH}$, specific surface area, and surface hydrophobicity. The electronegative surface of all tested biochars indicated that non-Coulombic mechanisms were involved in adsorption of the anionic or uncharged pharmaceuticals under experimental conditions. The adsorption capacities of Sulfapyridine (SPY), Docusate (DCT) and Erythromycin (ETM) on biochar were influenced by the contact time and solution $\mathrm{pH}$, as well as biochar specific surface area and functional groups. Adsorption of these pharmaceutical compounds was dominated by a complex interplay of three mechanisms: hydrophobic partitioning, hydrogen bonding and $\pi-\pi$ electron donor-acceptor (EDA) interactions. Despite weaker $\pi-\pi$ EDA interactions, reduced hydrophobicity of SPY and increased electrostatic repulsion between anionic SPY ${ }^{-}$and the electronegative $\mathrm{CG}$ biochar surface at higher $\mathrm{pH}$, the adsorption of SPY unexpectedly increased from $40 \%$ to $70 \%$ with an increase in $\mathrm{pH}$ from 7 to 10 . Under alkaline conditions, adsorption was dominated by the formation of strong negative charge-assisted H-bonding between the sulfonamide moiety of SPY and surface carboxylic groups. There seemed to be no appreciable and consistent differences in the extent of DCT and ETM adsorption as the $\mathrm{pH}$ changed. Results suggest the CG and GB biochars could act as effective adsorbents for the removal of pharmaceuticals from reclaimed water prior to irrigation. High surface area biochars with physico-chemical properties (e.g., presence of functional groups, high cation and anion exchange capacities) conducive to strong interactions with polar-nonpolar functionality of pharmaceuticals could be used to achieve significant contaminant removal from water.
\end{abstract}

Marlene C. Ndoun

mun99@psu.edu

1 Department of Agricultural and Biological Engineering, The Pennsylvania State University, 243 Agricultural Engineering Building, University Park, PA 16802, USA

2 USDA-ARS Arid Lands Agricultural Research Center, Maricopa, AZ 85138, USA

3 Department of Ecosystem Science and Management, The Pennsylvania State University, University Park, PA 16802, USA 


\section{Graphic Abstract}

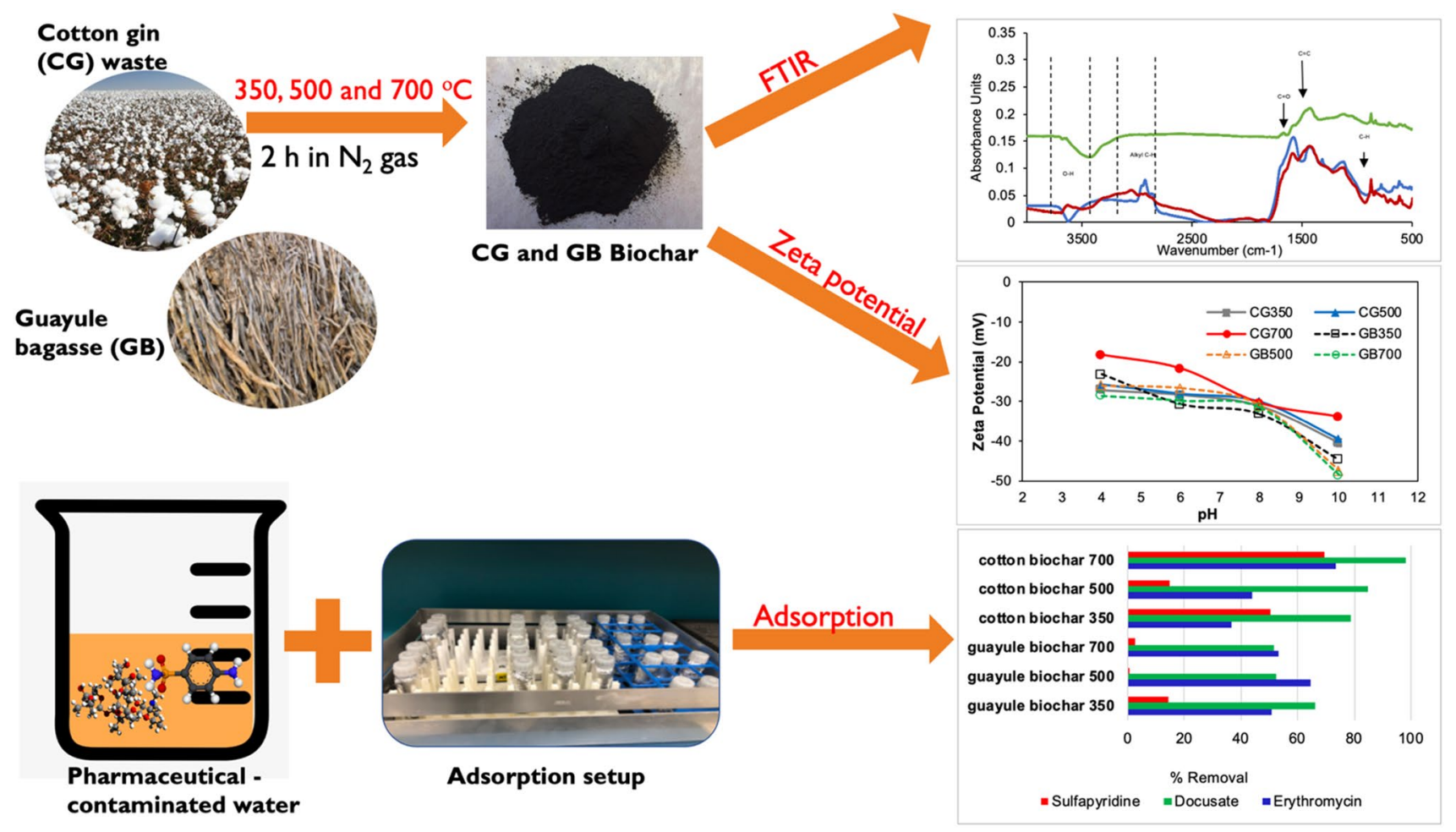

Keywords Biochar $\cdot$ Pharmaceuticals $\cdot$ Treated wastewater $\cdot$ Water treatment $\cdot$ Adsorption

\section{Highlights}

Biochar was obtained from the carbonization of cotton gin waste and guayule bagasse at three temperatures

Biochar shows considerable potential for the adsorption of SPY, DCT and ETM and can be used as a cheap, environmentally friendly adsorbent

Hydrophobic partitioning, electrostatic interactions, hydrogen bonding and $\pi-\pi$ electron donor-acceptor (EDA) interactions can simultaneously influence adsorption and determine the sorptive affinity of biochars for pharmaceuticals

\section{Introduction}

Anthropogenic activities, including increasing urbanization, population growth and intensive agricultural activities have introduced a broad range of emerging contaminants
(ECs) into the environment (Houtman 2010; Pal et al. 2010; Fenet 2012). ECs are defined as chemicals and microorganisms that have been detected in the environment and can potentially cause toxic effects in aquatic and human life at trace-level concentrations (ng- $\mu \mathrm{g} / \mathrm{L}$ levels), but for which no water quality regulations exist (Ahmed et al. 2017a; USGS, 2015). There are several classes of ECs including pesticides, industrial additives, flame retardants, endocrine disrupting compounds (EDCs) and pharmaceuticals and personal care products (PPCPSs). Among all classes of ECs, PPCPs are the most abundant in the environment and are often detected at elevated concentrations in surface and groundwaters (Daughton 2004) due to continuous human use. Additionally, wastewater treatment plants (WWTPs) are not effective at removing many of these chemicals, leading to the presence of various PPCPs in wastewater effluents (Gros et al. 2010; Sui et al. 2011).

The World Health Organization (WHO) estimated that in 2025, two-third of the world's population could be living in regions with limited access to water. Agriculture is the sector which requires the most water and is expected to be impacted by the shortage. To mitigate these impacts, treated wastewater or reclaimed water has become an important source of water for agricultural irrigation especially in 
arid regions of the world. Reclaimed water is wastewater from homes, offices, hospitals and industries that has undergone treatment to remove impurities such as nutrients and pathogens (DSWS 2011). Reclaimed water can be successfully used for irrigation because even after treatment, it still contains nitrogen and phosphorus that are essential to plant growth (Kinney et al. 2006).

When treated wastewater is used for irrigation, contaminants such as pharmaceuticals may be introduced into crops from the soil through root uptake and translocation, leading to accumulation of these contaminants not only in the roots, but also in edible above-ground plant parts (Bartha et al. 2010). Erythromycin, a commonly used antibiotic, was found to accumulate over 5 months in soil irrigated with reclaimed water (Kinney et al. 2006). A study by Gibson et al. (2010) demonstrated that wastewater reused for irrigation contains pharmaceuticals such as ibuprofen $(0.7-1.4 \mu \mathrm{g}$ $\left.\mathrm{L}^{-1}\right)$, naproxen $\left(7.2-13.5 \mu \mathrm{g} \mathrm{L}^{-1}\right)$ and diclofenac $(2.0-4.8 \mu \mathrm{g}$ $\mathrm{L}^{-1}$ ). In addition, runoff from irrigated farmlands has been shown to impact surface water bodies and leach into groundwater. A study by Kolpin et al. (2002) showed that organic contaminants, including PPCPs, were detected in $80 \%$ of a network of 139 streams located downstream of urban networks and livestock production. Another study in New York on streams receiving wastewater discharge showed the presence of sulfamethoxazole and clindamycin at concentrations varying between 0.043 and $0.076 \mu \mathrm{g} \mathrm{L}^{-1}$ (Batt et al. 2006). Continuous accumulation and persistence of these chemicals in the environment can lead to ecotoxicological risks such as interference with endocrine systems of higher organisms, intersex characteristics in organisms such as fish, and microbiological resistance among bacterial populations (Belhaj et al. 2015).

Continuing concerns regarding possible population-level impacts of pharmaceuticals from wastewater effluents has contributed to a search for sustainable and cheap technologies which will result in the effective removal of pharmaceuticals from reclaimed water. Recently, biochar has been explored as a potential material for the adsorption of pharmaceuticals from aqueous solutions (Ahmed et al. 2017a; Mondal et al. 2016; Mostafapour et al. 2019; Sumalinog et al. 2018; Taheran et al. 2016; Yanyan et al. 2018). Biochar is a stable carbon (C)-rich, energy dense by-product synthesized through the pyrolysis of waste biomass in the absence of oxygen (Lehmann and Joseph 2009). Biochar has been employed as an adsorbent and it has the ability to compete with activated carbons (ACs) for the removal of contaminants from water due to its microporous structure, high $\mathrm{C}$ content, and specific surface area. Research on biochar as a potential filter media for urban stormwater runoff demonstrated that biochar filters effectively remove total suspended solids, heavy metals, nutrients, polycyclic aromatic hydrocarbons, and E. coli (Mohanty and Boehm
2014; Reddy et al. 2014). Bolster (2019) demonstrated that adding biochar to sand columns enhanced the removal of bacterial isolates E. coli and Salmonella, with sorption being the primary mechanisms for bacteria removal. Studies have also reported the potential use of biochar as an adsorbent for the treatment of agricultural wastewater effluents. Particular attention has been given to the removal of pesticides from water using biochar, with reported sorption coefficients as high as $1158 \mathrm{mg} \mathrm{kg}^{-1}$ for atrazine and $1066 \mathrm{mg} \mathrm{kg}^{-1}$ for simazine (Zheng et al. 2010).

The cotton gin and guayule industries are viable sources of biomass for biochar. The production of textiles from cotton gin accounts for approximately 2.5 million metric tons of cotton gin waste being generated every year (Maglinao et al. 2015). A minimum 200 metric ton per day of guayule bagasse is discarded from the production of latex and biofuels from guayule (Sabaini et al. 2018). The enormous quantities of waste generated present several economic and environmental problems such as the cost associated with landfilling (e.g., tipping fees). Thus, the transformation of cotton gin waste and guayule bagasse into value-added products such as biochar for the treatment of wastewater used for irrigation warrants investigation.

The overall aim of this research was to investigate the use of biochars derived from cotton gin waste and guayule bagasse as filter media for removal of pharmaceuticals known to persist in wastewater effluent used for irrigation. Herein we investigate the effect of biochar pyrolysis temperature on important adsorption-related properties (surface area, porosity, surface charge and functionality, $\mathrm{pH}$ ). The biochars were then evaluated for their abilities to remove selected pharmaceuticals from aqueous solution using batch adsorption experiments. Mechanisms and kinetics governing the interaction between pharmaceuticals and biochars were elucidated. Based on our results, the utility of these biochars in sand filters for removal of pharmaceuticals from reclaimed water prior to irrigation of food crops is addressed.

\section{Materials and methods}

\subsection{Target adsorbates}

Three pharmaceuticals (sulfapyridine, docusate and erythromycin) were purchased from Sigma-Aldrich (St. Louis, MO, USA). These pharmaceuticals were selected due to their frequency of occurrence in environmental systems as a result of widespread usage. Additionally, their $\mathrm{pK}_{\mathrm{a}}$ values and octanol water-partition coefficients $\left(\log \mathrm{K}_{\mathrm{ow}}\right)$ cover broad ranges. The physico-chemical properties of the pharmaceuticals are provided in Table 1. 
Table 1 Physico-chemical properties and structures of pharmaceuticals

\begin{tabular}{|c|c|c|c|}
\hline Pharmaceuticals & Sulfapyridine (SPY) & Docusate (DCT) & Erythromycin (ETM) \\
\hline Molecular formula ${ }^{a}$ & $\mathrm{C}_{11} \mathrm{H}_{11} \mathrm{~N}_{3} \mathrm{O}_{2} \mathrm{~S}$ & $\begin{array}{l}\mathrm{C}_{20} \mathrm{H}_{37} \mathrm{NaO}_{7} \mathrm{~S} \\
\text { (Sodium salt) }\end{array}$ & $\mathrm{C}_{37} \mathrm{H}_{67} \mathrm{NO}_{13}$ \\
\hline $\begin{array}{l}\text { Molecular weight } \\
\left(\mathrm{g} \mathrm{mol}^{-1}\right)^{\mathrm{a}}\end{array}$ & 249.29 & 444.56 & 733.93 \\
\hline $\begin{array}{l}\text { Water solubility } \\
\left(\mathrm{mg} \mathrm{L}^{-1} \text { at } 25^{\circ} \mathrm{C}\right)^{\mathrm{a}}\end{array}$ & 268 & 71000 & 2000 \\
\hline $\mathbf{p K}_{\mathrm{a}}$ & $2.30^{b} 8.43^{b}$ & $10.84^{\mathrm{a}}$ & $8.88^{\mathrm{c}}$ \\
\hline $\log K_{\text {ow }}{ }^{a}$ & 0.35 & 5.24 & 3.06 \\
\hline \multicolumn{4}{|l|}{ Structure $^{a}$} \\
\hline \multicolumn{4}{|c|}{ (National Center for Biotechnology Information) } \\
\hline $\begin{array}{l}\text { Center for Biotechnology In } \\
\text { 1. 2017) } \\
\text { ind et al. 1997) }\end{array}$ & ormation) & & \\
\hline
\end{tabular}

\subsection{Adsorbents}

Biochars obtained from the pyrolysis of guayule (Parthenium argentatum) bagasse (GB) and cotton (Gossypium L.) gin (CG) waste were studied to compare their adsorption capacities for pharmaceuticals in batch adsorption experiments. The biochar samples were prepared according to Novak et al. (2012). All feedstocks were processed before pyrolysis through air-drying, grinding, and sieving to pass a $6 \mathrm{~mm}$ sieve. Between 0.5 and $1.5 \mathrm{~kg}$ of ground biomass were placed in a stainless-steel tray and pyrolyzed slowly at low heating rates $\left(0.05-0.1^{\circ} \mathrm{C}\right)$ using a gas tight retort (Lindberg/MPH, Riverside, MI) at three different temperatures 350,500 and $700{ }^{\circ} \mathrm{C}$ for $2 \mathrm{~h}$ under a stream of $\mathrm{N}_{2}$ gas. The resulting biochar samples are herein referred to as GB350, GB500, GB700, CG350, CG500 and CG700. The biochar samples were ground to pass a $0.5 \mathrm{~mm}$ sieve and stored in a desiccator to minimize water absorption.

\subsection{Characterization of biochar}

The $\mathrm{pH}$ of the biochar samples was measured following a modified procedure by Angin (2013). Biochars were added to deionized (DI) water in a mass ratio of 1:20 (0.5 g of biochar $+10 \mathrm{~mL}$ of water). The mixture was shaken for $1 \mathrm{~h}$ using a mechanical shaker and the $\mathrm{pH}$ was measured. The Brunauer-Emmett-Teller (BET) surface areas (SAs) and pore volumes of the biochar were determined using the ASAP 2020 plus surface area and porosimetry system (Micrometrics, Norcross, GA) and the accompanying t-plot analysis software.

The surface functional groups of the biochars were identified according to a modified procedure described by Kloss et al. (2012), using a Fourier transform infrared (FTIR; Bruker IFS 66/S and Bruker Vertex V70) spectrometer equipped with a liquid nitrogen cooled mercury cadmium telluride (MCT) detector. Experiments were carried out in diffuse reflectance mode on a Praying Mantis diffuse 
reflectance accessory. Sample powder was placed in a $3 \mathrm{~mm}$ diameter 316 stainless steel sample cup assembly and a total of 500 scans were averaged per spectrum at a resolution of $4 \mathrm{~cm}^{-1}$.

The zeta potential values of the samples were measured using Malvern Zetasizer ZS and according to a modified procedure by Johnson et al. (1996). The biochar samples were ground and sieved to pass a $34 \mu \mathrm{m}$ sieve. About $0.015 \mathrm{~g}$ of each biochar sample was added to $30 \mathrm{~mL}$ of DI water. Solution $\mathrm{pH}$ was adjusted using $0.05 \mathrm{M} \mathrm{HCl}$ or $\mathrm{NaOH}$. Zeta potential was measured three times at each $\mathrm{pH}$ (150 scans each time), with the average values reported.

\subsection{Batch adsorption experiments}

Batch adsorption experiments were conducted to determine the rate at which adsorption might reach equilibrium for the different biochars and pharmaceuticals. Stock solutions (200 $\mathrm{mg} \mathrm{L}^{-1}$ ) of SPY, DCT and ETM were diluted with DI water to produce initial concentrations of $10 \mathrm{mg} \mathrm{L}^{-1}$ for each pharmaceutical compound. While concentrations are relatively high compared to typical wastewater effluent concentrations, the initial concentration in this study was chosen for batch adsorption experiments to ensure that concentrations following adsorption were above the limit of detection. Single batch adsorption experiments were conducted to determine the adsorption kinetics for pharmaceuticals using $125 \mathrm{~mL}$ polytetrafluoroethylene (PTFE)lined ${ }^{\circledR}$ bottles containing $0.5 \mathrm{~g}$ of each biochar and $100 \mathrm{~mL}$ of solution containing $10 \mathrm{mg} \mathrm{L}^{-1}$ of each pharmaceutical. The mixtures were agitated at $200 \mathrm{rpm}$ using a mechanical shaker at ambient laboratory conditions $\left(\approx 23^{\circ} \mathrm{C}\right)$ and $10 \mathrm{~mL}$ aliquots (pharmaceutical solution + biochar) were collected after 5, 15, 30, 60, 120, 180, $240 \mathrm{~min}$ and $24 \mathrm{~h}$ contact times. Adsorption experiments were conducted in triplicates and PTFE-lined $®$ bottles were covered with aluminum foil to minimize photodegradation. Control treatments were included to investigate potential contamination or non-adsorption losses. Collected samples were filtered through a $1 \mu \mathrm{m}$ Whatman membrane filter and filtrates were analyzed by high-pressure liquid chromatography and mass spectrometry (HPLC-MS).

The pharmaceutical removal efficiency and amount adsorbed $\left(\mathrm{q}_{\mathrm{t}} ; \mathrm{mg} \mathrm{g}^{-1}\right)$ were calculated using Eqs. (1) and (2), respectively:

Removal efficiency $(\%)=\frac{C_{0}-C_{t}}{C_{0}} \times 100$

$q_{t}=\frac{C_{0}-C_{t}}{m} \times V$ where $C_{0}$ is the initial concentration of pharmaceuticals in solution $\left(\mathrm{mg} \mathrm{L}^{-1}\right), C_{t}$ is the concentration $\left(\mathrm{mg} \mathrm{L}^{-1}\right)$ at time $t$ $(5,15,30,60,120,180,240 \mathrm{~min}$ and $24 \mathrm{~h}), V$ is the volume of the solution (L) and $m$ is the mass of the biochar (g).

\subsection{Effect of solution pH}

The effect of solution $\mathrm{pH}$ on the adsorption of SPY, DCT and ETM was studied using CG700 biochar as the adsorbent. Batch adsorption experiments were conducted at the inherent solution $\mathrm{pH}$ ranging from $10-11$ and at $\mathrm{pH} 7$ to mimic the typically near-neutral conditions of wastewater effluents. The initial $\mathrm{pH}$ of the pharmaceutical solutions was adjusted to $\mathrm{pH} 7$ by adding $0.1 \mathrm{M} \mathrm{H}_{2} \mathrm{SO}_{4}$. Mixtures of $0.5 \mathrm{~g}$ of CG700 biochar in $100 \mathrm{~mL}$ of $10 \mathrm{mg} \mathrm{L}^{-1}$ stock solution of SPY, DCT and ETM were agitated at $200 \mathrm{rpm}$ on a mechanical shaker and then filtered at selected times between $5 \mathrm{~min}$ and $24 \mathrm{~h}$.

\subsection{Kinetic studies}

The kinetics of adsorption were analyzed using a pseudosecond-order (PSO) kinetic model, which is widely used for pollutant adsorption from aqueous solution (Ho 2006). Equation (3) shows the linearized form of the PSO kinetic rate equation:

$\frac{t}{q_{t}}=\frac{1}{k_{2} q_{e}^{2}}+t / q_{e}$

where $q_{e}$ and $q_{t}\left(\mathrm{mg} \mathrm{g}^{-1}\right)$ are the amounts of pharmaceuticals adsorbed per unit of mass of biochar at equilibrium and at time $t(\mathrm{~min})$, respectively, and $k_{2}\left(\mathrm{~g} \mathrm{mg}^{-1} \mathrm{~min}\right)$ is the rate constant of the PSO adsorption. From the PSO plot of $t / q_{t}$ versus $t$, the values of $q_{e}$ and $k_{2}$ were obtained from the slope and intercept, respectively. Model conformity was evaluated using the linear regression coefficients $\left(\mathrm{R}^{2}\right)$.

\subsection{Adsorption isotherms}

Adsorption isotherms of SPY, DCT and ETM on CG700 biochar were performed at room temperature. CG700 biochar $(0.5 \mathrm{~g})$ was added to SPY, DCT and ETM solutions $(100 \mathrm{~mL})$ of varying initial concentrations $(2,10,20,40$ and $50 \mathrm{mg} \mathrm{L}^{-1}$ ). Solutions were agitated for $24 \mathrm{~h}$ at $200 \mathrm{rpm}$ to reach equilibrium and then filtered. The equilibrium data obtained from the study were fitted to the Langmuir and Freundlich isotherms. The linear forms of the Langmuir and Freundlich models (Goswami et al. 2011) are represented by Eqs. (4) and (5):

$\frac{1}{q_{e}}=\frac{1}{q_{m}}+\frac{1}{K_{L} q_{m} C_{e}}$ 
$\log q_{e}=\log K_{f}+\frac{1}{n} \log C_{e}$

where $C_{e}\left(\mathrm{mg} \mathrm{L}^{-1}\right)$ is the equilibrium pharmaceutical concentration, $q_{e}$ and $q_{m}$ are the equilibrium and maximum adsorption capacity, respectively $\left(\mathrm{mg} \mathrm{g}^{-1}\right), K_{L}$ is the Langmuir adsorption equilibrium constant in $\mathrm{L} \mathrm{mg}^{-1}, K_{f}\left(\mathrm{mg} \mathrm{g}^{-1}\right)$ is the Freundlich constant related to adsorption capacity and $n$ is a measure of adsorption intensity.

\section{Results and discussion}

\subsection{Biochar characterization}

\subsubsection{Specific surface area $(\mathrm{SA})$ and $\mathrm{pH}$}

All biochar samples were alkaline and biochar $\mathrm{pH}$ increased with increasing pyrolysis temperature (Table 2). The basic nature of the biochar is due to the transformation of $\mathrm{C}$ into ash during pyrolysis and alkali salts begin to separate from the organic matrix, increasing the $\mathrm{pH}$ (Cao and Harris 2010). Porous structure (BET surface area and pore volume) of the studied biochar samples are summarized in Table 2.

The SAs of the cotton gin waste biochars were found to be low, but increased as the pyrolysis temperature increased to $700{ }^{\circ} \mathrm{C}$. Numerous studies have documented an increasing surface area of biochars with increasing pyrolysis temperatures (Ding et al. 2014; de Caprariis et al. 2017; Goswami et al. 2016; Kloss et al. 2012; Uchimiya et al. 2011). As the pyrolysis temperature reached $700{ }^{\circ} \mathrm{C}$, the BET SAs and number of micropores for the biochars significantly increased resulting from the removal of volatile matter that was either inside or blocking the micropores (Guedidi et al. 2017). Biochars obtained from guayule bagasse did not exhibit adequate SA and porous structure characteristics. This may be attributed to the softening, melting, fusing and carbonization which likely resulted in the pores of the biochar being partially blocked. This would prevent the access of the absorption gas to the pores and, therefore, lead to lower surface areas and pore volumes (Fu et al. 2011).
The SAs of the biochars were generally lower than values for biochars produced from various feedstocks used in other studies, although several biochars are reported to have values less than $10 \mathrm{~m}^{2} \mathrm{~g}^{-1}$. Uchimiya et al. (2011) reported SAs of biochar obtained from the pyrolysis of cottonseed hull at $350{ }^{\circ} \mathrm{C}$ and $500{ }^{\circ} \mathrm{C}$ to be 4.7 and $0.0 \mathrm{~m}^{2} \mathrm{~g}^{-1}$, respectively. Such low SAs do not preclude substantial adsorption of organic pollutants. Cao and Harris (2010) reported nearly $77 \%$ removal of atrazine $\left(1.5 \mathrm{mg} \mathrm{g}^{-1}\right.$ adsorption capacity) by dairy manure-derived biochar pyrolyzed at $200{ }^{\circ} \mathrm{C}$ with a SA of $2.7 \mathrm{~m}^{2} \mathrm{~g}^{-1}$.

\subsubsection{Zeta potential}

Figure 1 shows the $\mathrm{pH}$-dependent zeta potential of the biochars. The measured zeta potential for $\mathrm{CG}$ and GB was negative for all $\mathrm{pH}$ conditions tested. Increasing $\mathrm{pH}$ resulted in increasing negative zeta potential for all of the biochars. A similar $\mathrm{pH}$-dependent trend has been observed for pine wood biochars (Essandoh et al. 2015; Taheran et al. 2016). Given the nature of the $\mathrm{pH}$ dependence (Fig. 1), it was not possible to identify a $\mathrm{pH}$ point of zero charge (pHzpc) for the biochars. However, the relevance to the current research is that CG and GB biochar samples carry a net negative charge under all $\mathrm{pH}$ conditions used.

\subsubsection{FT-IR}

The FT-IR spectra of the biochar samples were used to characterize the surface functional groups. As shown in Fig. 2a,b, all spectra exhibit the $\mathrm{OH}, \mathrm{C}-\mathrm{H}, \mathrm{C}=\mathrm{O}$ and $\mathrm{C}=\mathrm{C}$, bond stretching at 3400, 2850,1750, $1600 \mathrm{~cm}^{-1}$, respectively. The peaks at about 3400 and $3550 \mathrm{~cm}^{-1}$ correspond to vibrations of $\mathrm{OH}$ groups and were still present in the biochar prepared at $700{ }^{\circ} \mathrm{C}$, but were dramatically straightened at 350 and $500^{\circ} \mathrm{C}$. The peak at $1770 \mathrm{~cm}^{-1}$ is due to the $\mathrm{C}=\mathrm{O}$ stretching vibrations of the carbonyls (aldehyde, ketones esters, carboxylic acids) both unconjugated and conjugated with aromatic rings (Uchimiya et al. 2011).

Carboxyl groups contribute to negative surface charge at circumneutral $\mathrm{pH}$ (Sect. 3.1.2) which promotes electrostatic adsorption of cations in aqueous solution. The absorbance
Table 2 BET surface area, pore size and $\mathrm{pH}$ of the biochars

\begin{tabular}{llllllr}
\hline Sample & Time (h) & $\mathrm{T}\left({ }^{\circ} \mathrm{C}\right)$ & $\begin{array}{l}\text { Surface area } \\
\left(\mathrm{m}^{2} \mathrm{~g}^{-1}\right)\end{array}$ & $\begin{array}{l}\text { Total pore vol- } \\
\text { ume }\left(\mathrm{cm}^{3} \mathrm{~g}^{-1}\right)\end{array}$ & $\begin{array}{l}\text { Average pore } \\
\text { diameter }(\mathrm{nm})\end{array}$ & $\mathrm{pH}$ \\
\hline Cotton gin (CG) waste & 2 & 350 & 2.40 & $3.10 \mathrm{E}-03$ & 4.07 & 9.46 \\
& 2 & 500 & 2.06 & $6.06 \mathrm{E}-03$ & 9.65 & 10.13 \\
& 2 & 700 & 16.33 & $1.15 \mathrm{E}-02$ & 3.59 & 10.93 \\
Guayule bagasse (GB) & 2 & 350 & 0.00 & $4.00 \mathrm{E}-05$ & - & 9.54 \\
& 2 & 500 & 0.07 & $1.70 \mathrm{E}-04$ & - & 9.89 \\
& 2 & 700 & 5.92 & $6.59 \mathrm{E}-03$ & - & 9.93 \\
\hline
\end{tabular}


Fig. 1 Zeta potential-pH curves of CG and GB biochar samples

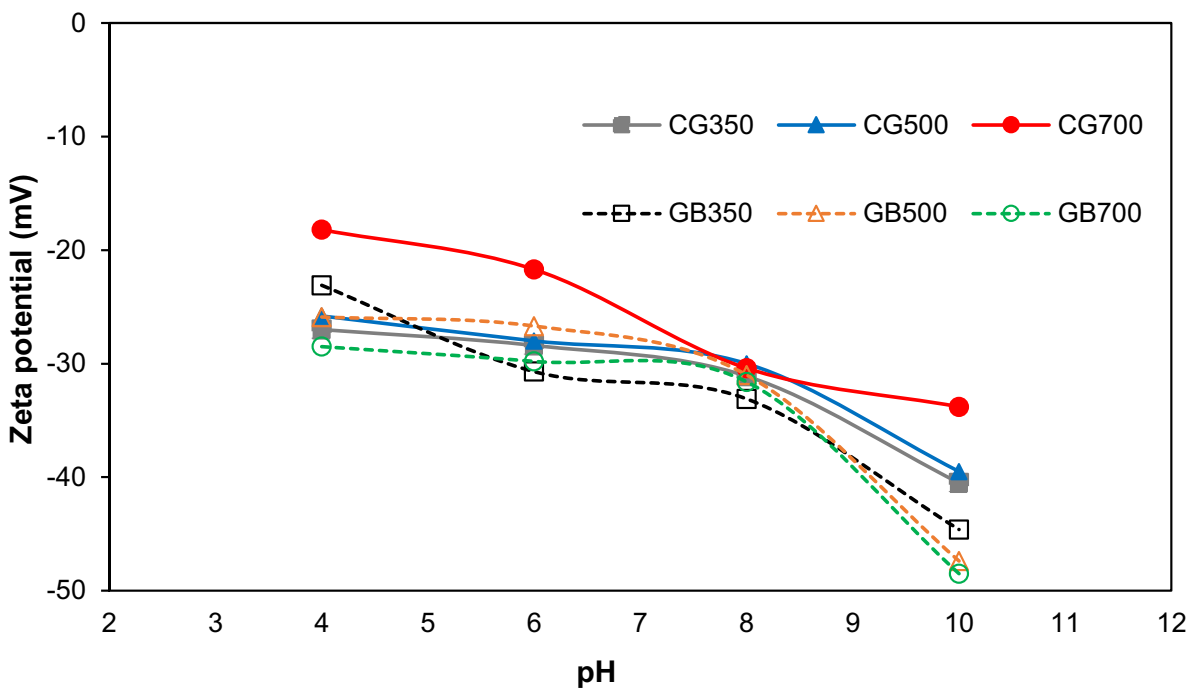

peaks between 1400 and $1500 \mathrm{~cm}^{-1}$ represent $\mathrm{C}=\mathrm{C}$ stretching vibrations indicative of alkanes and aromatics (Inyang et al. 2010). The $\mathrm{C}-\mathrm{O}$ stretching $\left(1350 \mathrm{~cm}^{-1}\right)$ occurred due to the presence of primary, secondary and tertiary alcohols, phenols, ethers and esters. The peak at wavenumber near $870 \mathrm{~cm}^{-1}$ reflects the $\mathrm{C}-\mathrm{H}$ bending vibration in $\beta$-glycosidic linkage (Krishnan and Haridas 2008). This also indicates the presence of adjacent aromatic hydrogen on the biochar surface.

The absorbance peak at $2850-2960 \mathrm{~cm}^{-1}$ indicates the presence of an alkyl $\mathrm{C}-\mathrm{H}$ and the intensity of this group decreased as temperatures increased from $350{ }^{\circ} \mathrm{C}$ to $500{ }^{\circ} \mathrm{C}$ and then to $700{ }^{\circ} \mathrm{C}$ (Fig. 2a, b). The $2850-2960 \mathrm{~cm}^{-1}$ peak area is strongly correlated to the hydrophobicity of the biochars (Kinney et al. 2012). From these results, it can be suggested that the increase of this functional group results from conversion of functional groups in a low oxidation state to those in a high oxidation state by means of heat treatment. The decrease of these functional groups at $700{ }^{\circ} \mathrm{C}$ was attributed to the release of these groups or conversion to other functionalities.

\subsection{Adsorption kinetics and mechanism}

Adsorption is a process governed by several mechanisms operating simultaneously and it is often difficult to precisely identify the role of each mechanism in a specific system. For interpreting adsorption behavior, it is convenient to consider the overall free energy for the adsorption reaction, $\Delta G_{\text {ads }}$, as a combination of terms representing various adsorption mechanisms:

$\triangle G_{\text {ads }}=\triangle G_{\text {elect }}+\triangle G_{\text {hydro }}+\triangle G_{\mathrm{H}-\text { bond }}+\triangle G_{\pi-\pi \mathrm{EDA}}+\ldots$ where $\Delta G_{\text {elect }}$ is the electrostatic adsorption term, $\Delta G_{\text {hydro }}$ accounts for removal from solution due to hydrophobic interaction, $\Delta G_{\mathrm{H} \text {-bond }}$ accounts for adsorption due to hydrogen bonding and $\Delta G_{\pi-\pi \mathrm{EDA}}$ accounts for electron-donor-acceptor interactions. The adsorption behaviors of DCT, SPY and ETM using CG and GB biochars are interpreted based on the interplay of these different mechanisms.

\subsubsection{Sulfapyridine (SPY) adsorption}

The time-dependent removal of SPY from solution using the six biochars is shown in Fig. 3a, b. The data indicates that the highest removal of SPY by biochar was observed with the CG700 (70\% removal), followed by CG350 (50\% removal) and CG500 (15\% removal) (Fig. 3a). Removal was correlated to the surface areas of the adsorbents that follow the same order CG700 > CG350 > CG500 (Table 2). The pyrolysis at $700{ }^{\circ} \mathrm{C}$ increased the surface area eightfold compared to the surface area at $350{ }^{\circ} \mathrm{C}$ and this was accompanied by an increase of approximately $20 \%$ in the extent of adsorption.

Binding of the SPY to the biochars is initially explained by the surface charge of the biochars and the properties of $\mathrm{SPY}^{-} ; \log K_{\mathrm{ow}}(0.35)$ and acidity constants $\left(\mathrm{pK}_{\mathrm{a} 1}=2.30\right.$; $\mathrm{pK}_{\mathrm{a} 2}=8.43$ ). The ionic character of SPY varies greatly with $\mathrm{pH}$, as reflected by the acidity constants. At the inherent solution $\mathrm{pH}$ which varied between $8.3-11.2$ over a $24 \mathrm{~h}$ contact time using CG700 and CG350, SPY exists mainly in its neutral and anionic forms $\left(\mathrm{pH}>\mathrm{pK}_{\mathrm{a} 1}\right.$ and $\mathrm{pK}_{\mathrm{a} 2}$; $\left.\mathrm{SPY}^{-}\right)$ and hydrophobic interactions caused by solvation of apolar molecular surfaces between SPY and the negatively charged biochar surfaces $(\mathrm{pH}>\mathrm{pHzpc})$ resulted in SPY adsorption (Yao et al. 2017). However, the amount of SPY adsorbed by CG700 and CG350 (Fig. 3a) is greater than what would be expected due to hydrophobic interactions alone, because 
Fig. 2 (a) FT-IR spectra of CG350, CG500 and CG700. (b) FT-IR spectra of GB350, GB500 and GB700

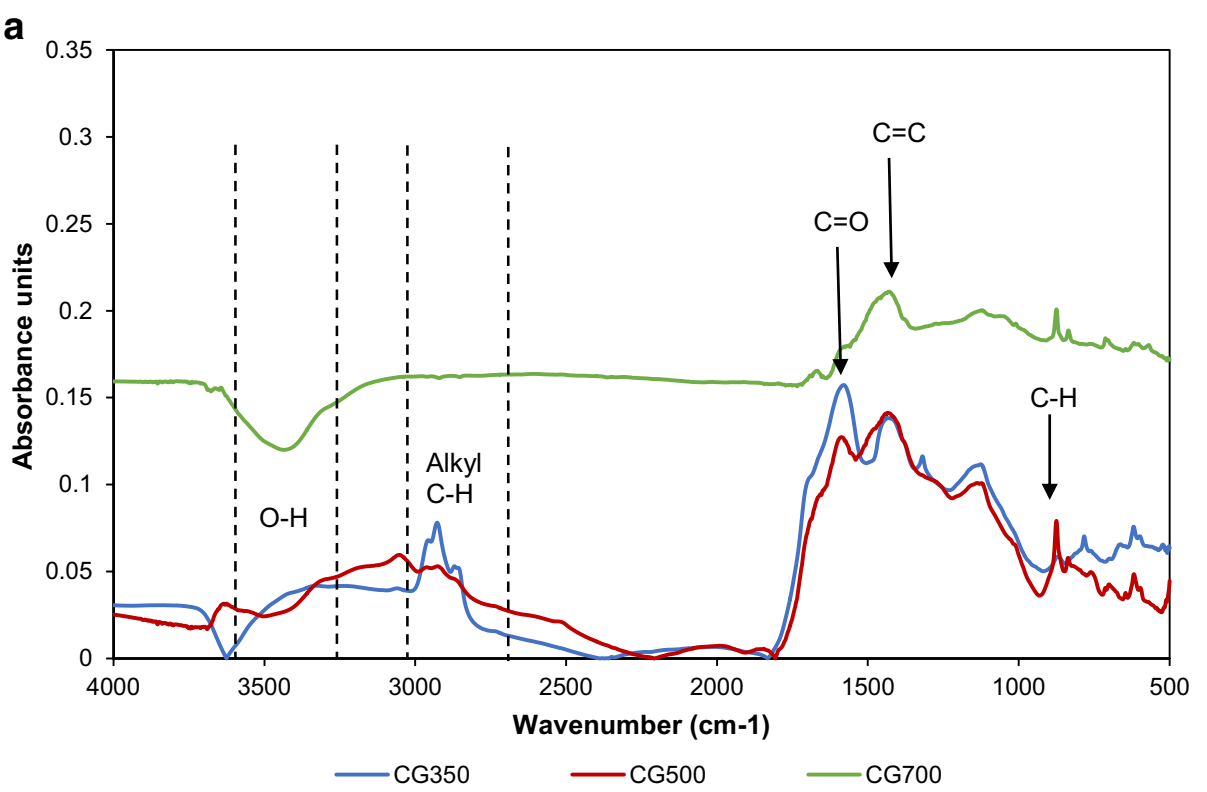

a FT-IR spectra of CG350, CG500 and CG700

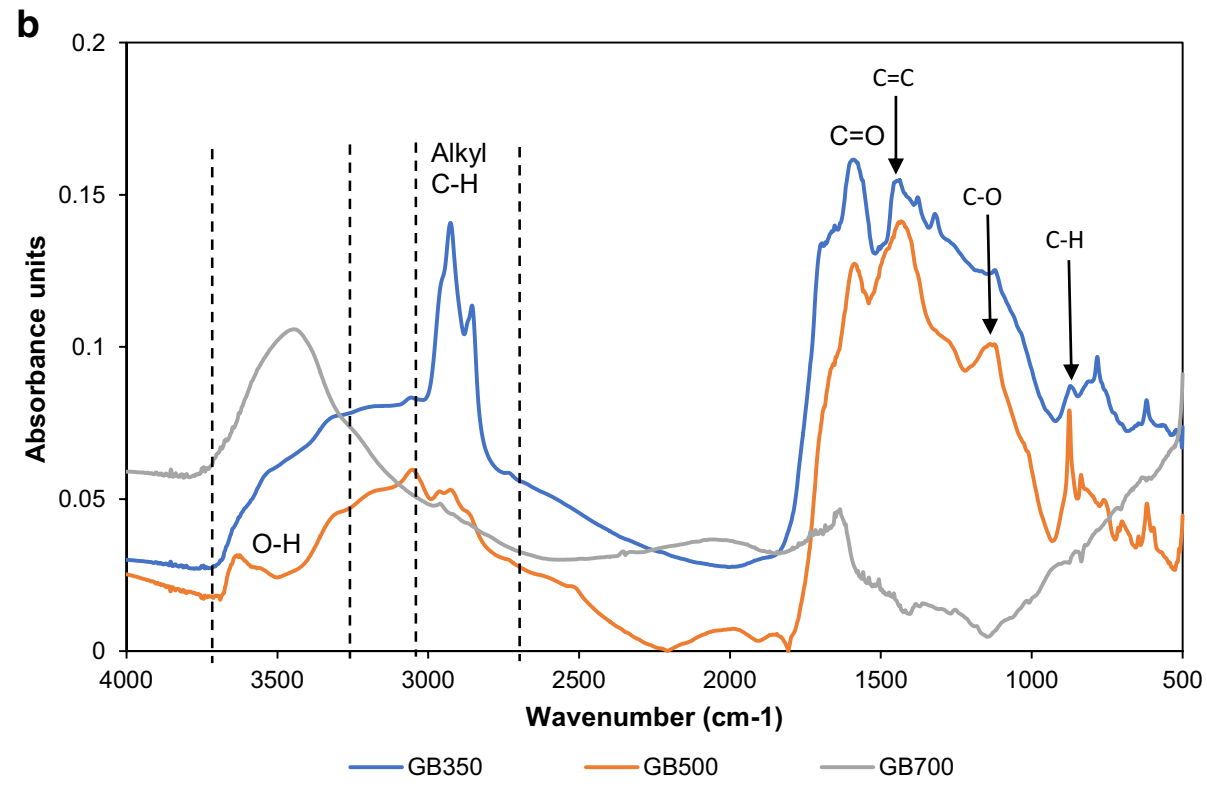

b FT-IR spectra of GB350, GB500 and GB700

Fig. 3 Removal of Sulfapyridine by (a) CG700, CG500 and CG350 and (b) GB700, GB500 and GB350 (Red errors bars $<10 \%$ )
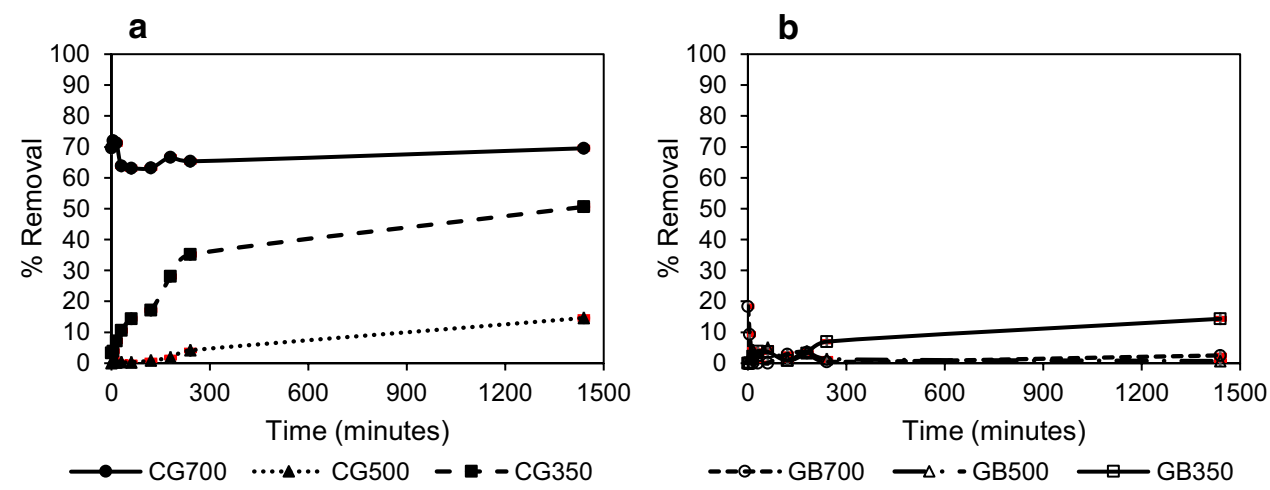
SPY has a $\log K_{\text {ow }}$ value of 0.35 . This suggests that other mechanisms are responsible for the removal of SPY from solution.

An additional binding mechanism for SPY removal is the formation of negative charge-assisted $\mathrm{H}$-bonds (CAHB) between the anionic SPY and the O-containing functional groups of the biochars. CAHB occurred in response to the elevation in $\mathrm{pH}$ as the contact time increased to $24 \mathrm{~h}$. The increase in $\mathrm{pH}$ is attributed to the release of $\mathrm{OH}^{-}$during the proton exchange between SPY ${ }^{-}$and water molecules, which is followed by interaction of the SPY molecules with the O-functional groups present on the biochar surface leading to $\mathrm{SPY}$ adsorption $\left(\mathrm{SPY}^{-}+\right.$biochar $\rightarrow \mathrm{SPY}^{\circ} \equiv$ biochar; Teixidó et al. 2011).

Furthermore, the sorption of SPY by CG700, CG500 and CG350 can be explained by $\pi-\pi$ electron-donor acceptor (EDA) interactions. SPY can act as a $\pi$-electron acceptor due to the presence of the amino functional group and $N$ and/or $O$-hetero-aromatic rings (Ahmed et al. 2017a, b). CG700, CG500 and CG350 biochars enriched with $\mathrm{C}=\mathrm{C}, \mathrm{OH}, \mathrm{C}=\mathrm{O}$ groups act as strong electron donors. Both of these factors may have facilitated $\pi-\pi \mathrm{EDA}$ interactions between CG700, CG500 and CG350 and SPY resulting in the removal from SPY from solution. Yao et al. (2017) recently proposed that the adsorption of SPY and sulfamethoxazole (SMX) onto biochars derived from anaerobically digested bagasse was due to $\pi-\pi$ EDA interactions between graphitic regions of biochars and the sulfonamide group in SMX and SPY. Ji et al. (2009) also reported that the adsorption of SMX and SPY to graphite and carbon nanotubes is enabled by $\pi-\pi$ EDA interactions involving the heterocyclic rings of the antibiotics.

The low removal by CG500 (14\% after $24 \mathrm{~h}$ ) compared to CG700 and CG350 might be attributed to the inherent $\mathrm{pH}$ of the solution. The $\mathrm{pH}$ varied between 8.79 and 9.30 from the beginning of the experiment to the final time. This is lower than the inherent solution pH using CG700 and CG350 (pH between 10.5-11.2 and 9.9-11.1, respectively). Consequently, with the $\mathrm{pH}$ being slightly above the $\mathrm{pK}_{\mathrm{a} 2}$ of SPY (8.4), a significant fraction of SPY exists as neutral species which do not participate in negative charge-assisted H-bonding. It is therefore hypothesized that adsorption of SPY by CG500 occurred primarily via two mechanisms (hydrophobic interaction and $\pi-\pi$ EDA interactions) instead of the three mechanisms attributed to the removal using CG700 and CG350 (hydrophobic interaction, CAHB and $\pi-\pi$ EDA interactions).

Differences in adsorption of SPY between CG and GB are correlated to the different physico-chemical characteristics of these biochars, which are predominantly controlled by the inherent molecular configuration of the plant-based biomass feedstock. GB700, GB500 and GB350 are characterized by more O-containing functional groups (Fig. 2b) compared to CG biochars, which renders GB biochars more hydrophilic and limits the potential for hydrophobic interaction. This is explained by the fact that during adsorption, the oxygen groups on the biochar surfaces usually act as the primary adsorption center. Water molecules show a greater affinity for surface oxygen groups on the biochar via hydrogen bonding compared to the more hydrophobic SPY molecules. Water molecules are therefore adsorbed onto the GB biochars surfaces and act as polarized secondary adsorption centers, promoting further water-molecule adsorption and cluster formation. These clusters form an envelope extending beyond the localized adsorption centers, reducing the accessibility of SPY molecules to the solid particles (Zheng et al. 2013). Moreover, water molecules strongly compete for adsorption sites with SPY on the functionalized biochar surface. As a result, the potential for hydrophobic interaction between SPY molecules and the GB biochars was strongly inhibited (Wu and Pendleton 2001). One additional factor is that low pore volume and specific surface areas of the GB700 $\left(5.92 \mathrm{~m}^{2} \mathrm{~g}^{-1}\right)$ GB500 $\left(0.06 \mathrm{~m}^{2} \mathrm{~g}^{-1}\right)$ and GB350 $\left(0.00 \mathrm{~m}^{2} \mathrm{~g}^{-1}\right)$ compared to the CG700 $\left(16.33 \mathrm{~m}^{2} \mathrm{~g}^{-1}\right)$, made the active sites less available for SPY adsorption, thereby resulting in minimal removal (Fig. 3b).
Fig. 4 Removal of Docusate by (a) CG700, CG500 and CG350 and (b) GB700, GB500 and GB350 (Red errors bars $<10 \%$ )
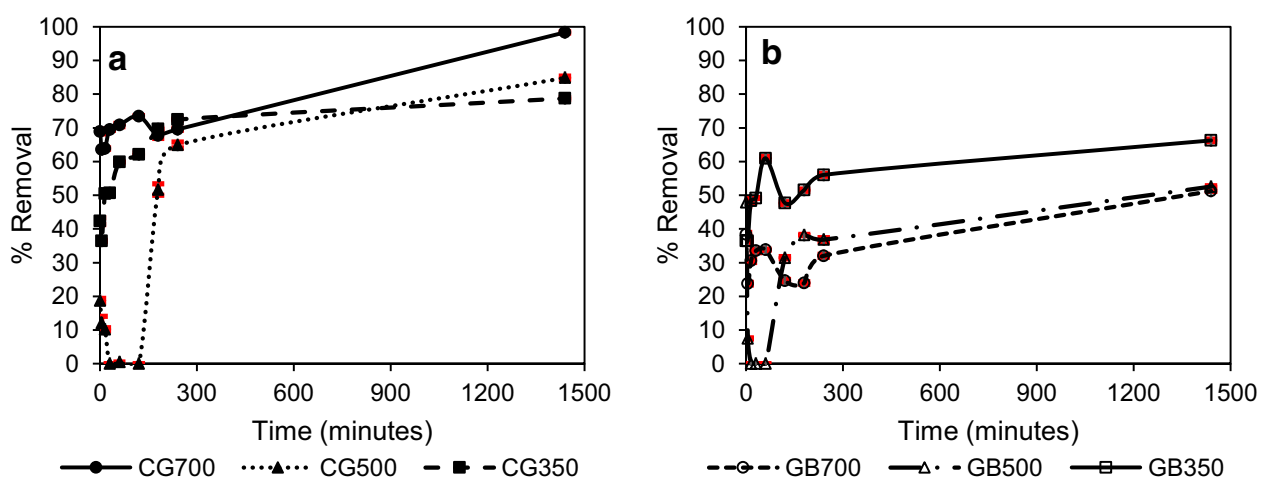


\subsubsection{Docusate (DCT) adsorption}

All tested biochars exhibited some ability to remove aqueous DCT (Fig. 4a, b). The removal of DCT reached 98\% using CG700, followed by $85 \%$ and $79 \%$ using CG500 and CG350, respectively (Fig. 4a). The biochar surfaces have a net negative charge (Fig. 1) and DCT, containing a strongly acidic sulfonate group (Table 1), is anionic over a wide $\mathrm{pH}$ range. For DCT to be adsorbed, it is likely that hydrophobic interactions are involved.

The hydrophobic nature of the CG700, CG500 and CG350 biochars (Table 2), compared to GB biochars, coupled with the relatively high $\log K_{\mathrm{ow}}$ (5.24) for DCT, aided in its adsorption. DCT has a greater tendency to withdraw from the aqueous phase compared to the other selected pharmaceuticals, facilitating hydrophobic interaction between the hydrophobic moiety of the surfactant DCT and the hydrophobic regions of the biochar surface. In addition, hydrophobic interactions can occur between the hydrophobic moiety of previously adsorbed DCT and other DCT molecules in solution, resulting in multilayer adsorption (Brown et al. 1998).

Moreover, even the GB biochars showed more than 50\% removal after $24 \mathrm{~h}$ (Fig. 4b). Adsorption using GB700, GB500 and GB350 reached 51\%, 53\% and 66\%, respectively. However, GB biochars showed the least removal, likely due to the presence of the additional $\mathrm{O}$-containing functional group. The predominance of $\mathrm{O}$-containing functional groups on the GB biochar causes a reduction in the hydrophobic character of the carbon surface, which, in turn, militates against the development of hydrophobic interactions between GB700, GB500 and GB350 and DCT. This resulted in lower DCT removal compared to the CG biochars.

The lower temperature biochar, GB350, showed the greatest removal of DCT compared to GB700. Besides the parent feedstock used to produce biochar, the pyrolysis temperature can also influence the surface area and natural organic matter (NOM) content of biochar. This will, in turn, affect the removal of DCT. Biochars made at lower pyrolysis temperatures contain higher NOM content and can sorb organic compounds through the mechanism of partitioning into the organic phase in contrast to hydrophobic interactions (Kupryianchyk et al. 2016). Thus, lower temperature GB350 biochar could have higher DCT adsorption potential due to its higher NOM content. The higher sorption of DCT onto lower temperature biochars suggests that surface functional groups on the biochars and NOM may play a more important role in interactions between DCT and biochar than other factors, such as specific SA. No research addressing the adsorption of DCT onto biochar could be found; therefore, further investigation of binding mechanisms is warranted.

\subsubsection{Erythromycin (ETM) adsorption}

The ETM adsorption profiles onto CG700, CG500 and CG350 biochars show 74\%, 44\% and 37\% removal, respectively (Fig. 5a). Using the GB biochars, removal reached $53 \%, 64 \%$ and $50 \%$ for GB700, GB500 and GB350, respectively (Fig. 5b). Since ETM has a $\mathrm{pK}_{\mathrm{a}}$ value of 8.88 and the inherent experimental $\mathrm{pH}$ of the solution varied between 10.2 and 11.4 when using the biochars, ETM existed predominantly in its anionic form. Since the biochar surface also carries a net negative charge (Fig. 1), electrostatic attraction is precluded. Consequently, adsorption is in response to hydrophobic interactions induced by van der Waals forces arising between the hydrophobic ETM molecules $\left(\log \mathrm{K}_{\mathrm{ow}}=3.06\right)$ and the negatively charged graphemic planes of hydrophobic biochars (Sun et al. 2009).

The adsorption of ETM onto microporous hydrophobic beads studied by Sun et al. (2009) showed that increasing the temperature and $\mathrm{pH}$ resulted in decreased $K_{\mathrm{d}}$, indicating that more ETM molecules were present in the solution and that adsorption occurred due to van der Waals forces. In addition, the adsorption of ETM onto the biochars is increased by rapid diffusion of ETM molecules from the solution into the porous structures of the biochars (Mostafapour et al. 2019). Moreover, ETM has the ability to form hydrogen bonds between its hydroxyl moieties and the $(\mathrm{C}=\mathrm{O})$ and $(\mathrm{C}=\mathrm{C})$ group present on the biochars surfaces. The adsorption of ETM follows the order CG700 > GB50
Fig. 5 Removal of Erythromycin by (a) CG700, CG500 and CG350 and (b) GB700, GB500 and GB350 (Red errors bars $<10 \%)$
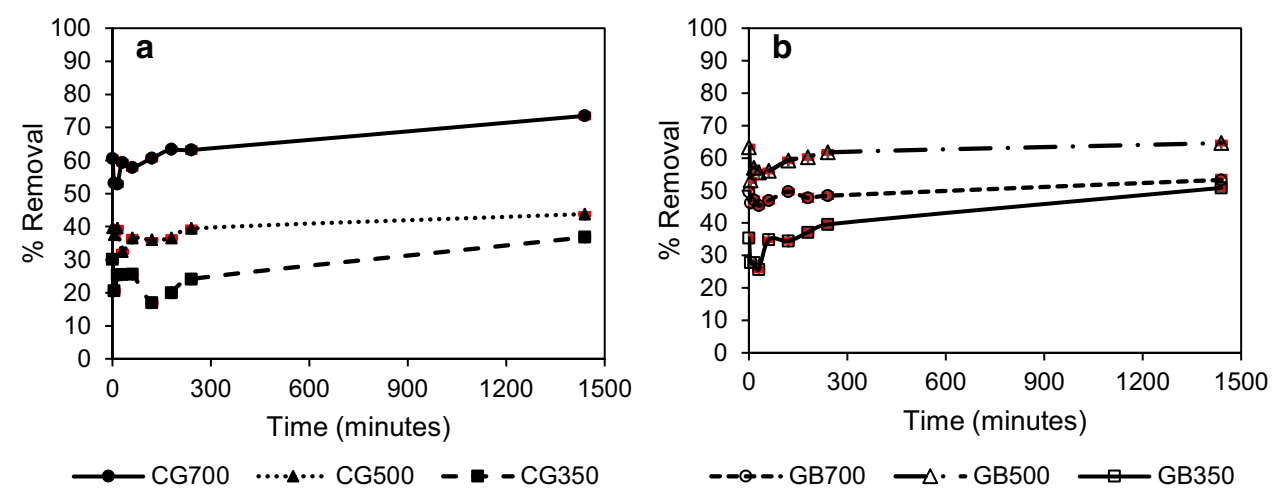
$0>\mathrm{GB} 700>\mathrm{GB} 350>\mathrm{CG} 500>\mathrm{CG} 350$. Apart from the CG700, the more hydrophilic GB biochars removed ETM more than the CG biochars. These results indicate that the more O-containing functional groups present on the GB biochar increased the formation of H-bonds, thereby leading to greater removal. Moreover, this suggests that adsorption might be dominated by the formation of $\mathrm{H}$-bonds and not the availability of active surface sites.

\subsection{Modeling kinetics and adsorption isotherms}

\subsubsection{Kinetics modeling}

Quantifying the rate of pharmaceutical removal is necessary for modeling adsorption and determining the contact time needed to achieve a desired amount of pharmaceutical removal in water treatment processes. In this study, both PFO and PSO kinetic models were employed to model the experimental data but only the PSO results are shown (Table 3), since the $R^{2}$ values for the PFO model are low.

From the results, it can be deduced that the PSO model could be used to explain the adsorption processes onto almost all of the biochars because of the high $R^{2}$ values $(>0.8)$, with the exception of a few cases. It is also observed from Table 3 that the experimental adsorption capacity $\left(q_{\mathrm{e}(\exp )}\right)$ value is very close to the model-calculated adsorption capacity $\left(q_{\mathrm{e} \text { (cal) }}\right)$ for SPY, DCT and ETM,

Table 3 Kinetic parameters of pseudo-second-order model for the adsorption of the selected pharmaceuticals, SPY, DCT and ETM

\begin{tabular}{lllclc}
\hline Biochar & EC & $\begin{array}{l}q_{\text {e(exp) }}(\mathrm{mg} \\
\left.\mathrm{g}^{-1}\right)\end{array}$ & \multicolumn{2}{c}{ Pseudo-second-order kinetic model } \\
\cline { 3 - 6 } & & & $\begin{array}{l}k_{2}(\mathrm{~g} \\
\left.\mathrm{mg}^{-1} \mathrm{~h}^{-1}\right)\end{array}$ & $\begin{array}{l}q_{\text {e (cal) }}(\mathrm{mg} \\
\left.\mathrm{g}^{-1}\right)\end{array}$ & $R^{2}$ \\
\hline CG700 & SPY & 0.785 & 3.176 & 0.766 & 0.997 \\
& DCT & 2.086 & 2.115 & 2.143 & 0.999 \\
& ETM & 1.923 & 2.034 & 1.934 & 0.991 \\
GB700 & SPY & 0.018 & 90.134 & 0.017 & 0.848 \\
& DCT & 0.989 & 0.893 & 1.011 & 0.972 \\
& ETM & 1.395 & 5.095 & 1.398 & 0.999 \\
CG500 & SPY & 0.094 & 1.743 & 0.114 & 0.863 \\
& DCT & 0.596 & 0.598 & 7.025 & 0.972 \\
& ETM & 0.907 & 4.740 & 0.912 & 0.999 \\
GB500 & SPY & 0.013 & 96.579 & 0.013 & 0.987 \\
& DCT & 1.097 & 2.818 & 1.096 & 0.986 \\
& ETM & 1.752 & 5.247 & 1.757 & 0.999 \\
CG350 & SPY & 1.073 & 0.419 & 1.151 & 0.976 \\
& DCT & 2.019 & 1.823 & 2.037 & 0.999 \\
& ETM & 0.712 & 1.436 & 0.726 & 0.979 \\
GB350 & SPY & 0.285 & 0.896 & 0.311 & 0.802 \\
& DCT & 1.437 & 2.023 & 1.448 & 0.998 \\
& ETM & 1.169 & 1.527 & 1.185 & 0.996 \\
\hline
\end{tabular}

which is consistent with the high correlation of the adsorption of pharmaceuticals onto biochars to the PSO model. The better fit of the experimental data by the PSO model implies that the adsorption of SPY, DCT and ETM onto CG and GB biochars was a rate-limited process controlled by chemical adsorption involving sharing or exchange of electrons between pharmaceuticals and biochars (Qiu et al. 2009). The results for the PSO model fitting for the adsorption of the SPY onto GB700, CG500 and GB350 biochars are less favorable $\left(R^{2}<0.9\right)$ compared to the adsorption of SPY, DCT and ETM onto CG biochars $\left(R^{2}>0.9\right)$. This less favorable fit may be attributed to the irregular variation of the adsorption results characterized by very low removal, followed by high removal efficiencies and then no removal, leading to a flat horizontal line showing $0 \%$ additional removal after $24 \mathrm{~h}$. The adsorption kinetics do not plateau, and therefore determining the values of $R^{2}$ and $q_{\text {e (cal) }}$ becomes difficult.

No kinetic studies could be found on adsorption of SPY, DCT and ETM onto cotton gin waste and guayule bagasse biochars. Nonetheless, other researchers have reported that the PSO model is useful for describing the adsorption of pharmaceuticals onto different adsorbents. The sorption of sulfonamides by functionalized biochar followed the PSO chemisorption kinetic model (Ahmed et al. 2017b). Reguyal et al. (2017) found that the removal of sulfamethoxazole (SMX) and sulfamethazine (SMT) by magnetized pine saw dust biochar followed the PSO model. The adsorption of ETM by carbon nanotubes was better explained by the PSO model $\left(R^{2}=0.995\right)$ compared to the PFO with an $R^{2}$ value of 0.892 (Mostafapour et al. 2019). Therefore, our results are consistent with other previous findings.

\subsubsection{Adsorption isotherms}

The adsorption isotherm represents the relationship between the mass of pharmaceuticals adsorbed per unit weight of biochar and liquid-phase equilibrium concentration of the pharmaceuticals. These isotherms provide important design data for adsorption systems (Lata et al. 2007). When SPY, DCT and ETM concentrations in the aqueous solutions were increased from 2 to $50 \mathrm{mg} \mathrm{L}^{-1}$, adsorptive uptake of the CG700 also increased. Table 4 shows the different isotherm parameters and their corresponding values. It is seen from Table 4 that the Langmuir isotherm model (Fig. 6a) exhibited a better fit (i.e., a higher $\mathrm{R}^{2}$ ) to the adsorption data than the Freundlich isotherm model (Fig. 6b). The data obtained from the Langmuir isotherm model produces a straight line fitted with higher $R^{2}$ of $0.962,0.966$ and 0.989 for SPY, DCT and ETM, respectively, and this clearly suggests that the Langmuir isotherm validates the experimental data for the adsorption of pharmaceuticals onto CG700 biochar. The maximum SPY, DCT and ETM adsorption capacities $\left(q_{m}\right)$ 
Table 4 Related parameters Langmuir and Freundlich isotherm model for erythromycin and docusate adsorption on to CG700

\begin{tabular}{llll}
\hline Langmuir isotherm & $q_{\mathrm{m}}\left(\mathrm{mg} \mathrm{g}^{-1}\right)$ & $K_{\mathrm{L}}\left(\mathrm{L} \mathrm{mg}^{-1}\right)$ & $R^{2}$ \\
\hline ETM & 17.123 & 0.016 & 0.989 \\
DCT & 19.685 & 0.374 & 0.966 \\
SPY & 1.221 & 1.681 & 0.962 \\
\hline Freundlich isotherm & $K_{\mathrm{f}}\left(\mathrm{mg} \mathrm{g}^{-1}\right)$ & $n$ & $R^{2}$ \\
\hline ETM & 0.337 & 1.333 & 0.947 \\
DCT & 2.957 & 1.847 & 0.905 \\
SPY & 0.531 & 3.632 & 0.909 \\
\hline
\end{tabular}

Fig. 6 Adsorption isotherms of ETM, DCT and SPY (secondary axis) removal by CG700 (a) Langmuir and (b) Freundlich isotherm
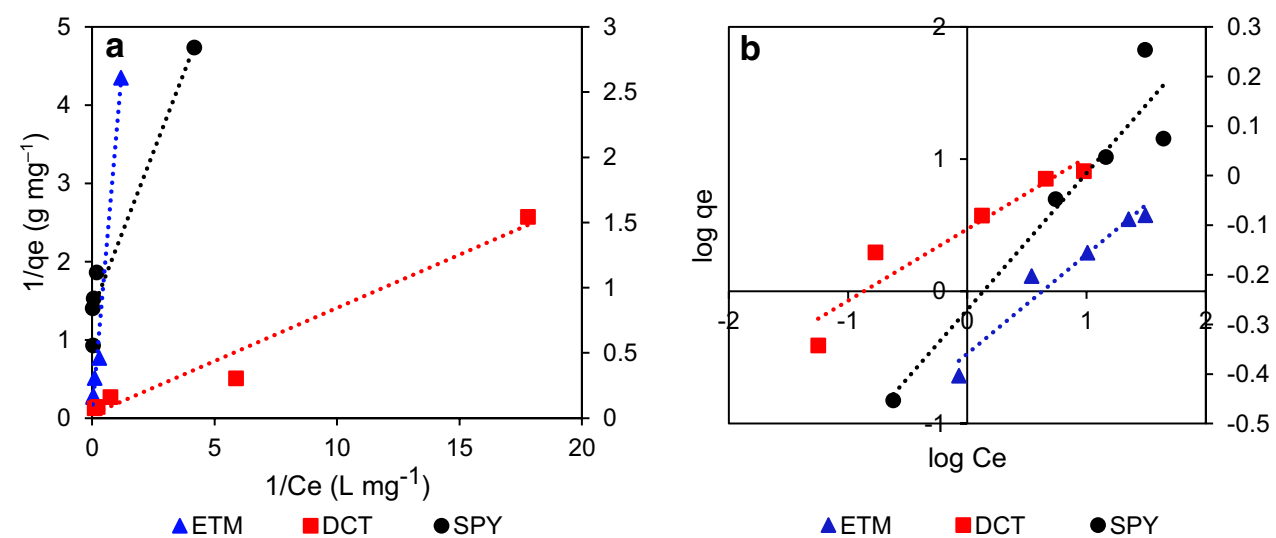

were $1.221,19.685$ and $17.123 \mathrm{mg} \mathrm{g}^{-1}$, respectively. The value $q_{m}$ for DCT suggests a greater affinity between DCT molecules and CG700 compared to ETM and SPY molecules. These results are in accordance with the results from the adsorption of the pharmaceuticals showing 98\% DCT removal after $24 \mathrm{~h}$ (Sect. 3.2.2). The adsorption data fitting the Langmuir isotherm suggests that there is uniform binding energy on the surface of the adsorbent and negligible sorbate-sorbate interaction which, in turn, facilitates physical monolayer adsorption (Gong et al. 2008).

The suitability of the Freundlich model for SPY, DCT and ETM is indicated by $R^{2}$ values of $0.909,0.905$ and 0.947 , respectively. The Freundlich constants $\left(K_{f}\right)$ for SPY, DCT and ETM are $0.531,2.957$ and $0.337 \mathrm{mg} \mathrm{g}^{-1}$, respectively, and the $n$ values lie between 1 and 10 signifying favorable adsorption by CG700. There is a stronger affinity between DCT and CG700 which is demonstrated by the larger $K_{f}$ value for DCT compared to ETM and SPY. The Freundlich isotherm model suggests that adsorption of these pharmaceuticals onto the surface of CG700 is considered to be a multi-layer, chemisorption process in which the amount of pharmaceuticals absorbed per unit mass of the CG700 increases gradually and is not restricted to the formation of the monolayer (Chung et al. 2015).

The data fitting both isotherm models $\left(R^{2}>0.9\right)$ indicates that the adsorption of pharmaceuticals on CG700 biochar is not restricted to physical monolayer adsorption and that chemical interactions may be involved. Other studies (Wang et al. 2010; Liu et al. 2012) have reached similar conclusions. Caution is warranted in choosing one isotherm model over another to explain the adsorption mechanism, given the fact that linear and nonlinear models give different correlation coefficients and this leads to difficulties in explaining the adsorption mechanism as it relates to isotherms (Foo and Hameed 2010). However, once the isotherm parameters are determined, these parameters can be used as constants and experimental conditions such as initial pharmaceutical concentrations and biochar mass required to achieved desired removal efficiencies could be estimated prior to the actual adsorption process. This is particularly useful when designing columns for scaling the adsorption process (Essandoh et al. 2015).

\subsection{Effect of solution pH}

Solution $\mathrm{pH}$ affects both the ionization of the pharmaceuticals and the surface charge of the biochars which, in turn, influences the different mechanisms for pharmaceutical adsorption onto biochar. The removal of SPY was approximately $70 \%$ at $\mathrm{pH} 10-11$ but was significantly reduced $(40 \%)$ at pH 7 (Fig. 7a). These results differ from other previous studies, with several reporting a decrease in SPY adsorption 
Fig. 7 Removal of (a) Sulfapyridine, (b) Docusate and (c) Erythromycin on CG700 at $\mathrm{pH} 7$ and 10 (Red errors bars $<10 \%$ )
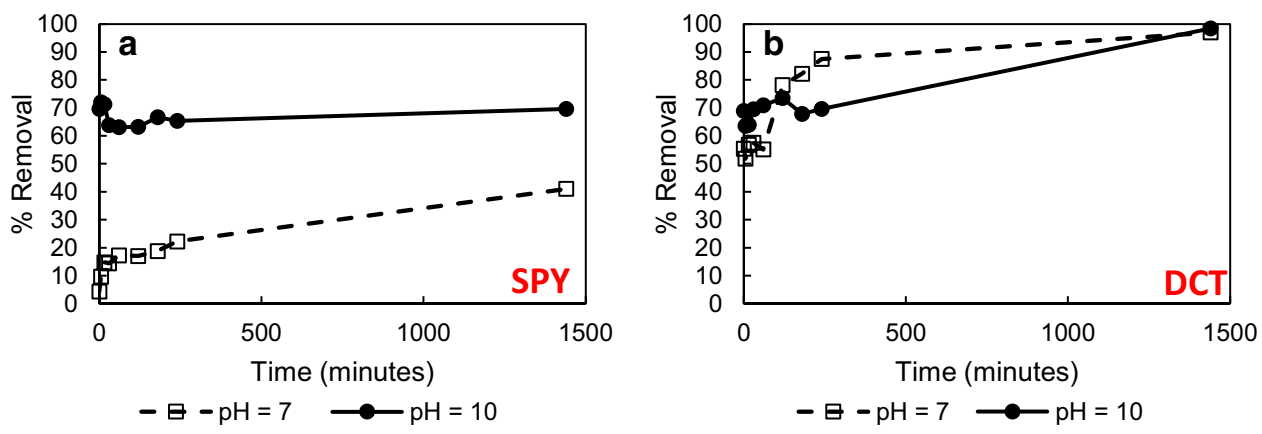

with a rise in $\mathrm{pH}$ due to increased electrostatic repulsion between the anionic SPY ${ }^{-}$and the negatively charged biochar surface (Ji et al. 2009; Xie et al. 2014; Yao et al. 2017). Additionally, anionic $\mathrm{SPY}^{-}$present at higher $\mathrm{pH}$ is more hydrophilic than the neutral form (present at lower $\mathrm{pH}$ ), which causes a decrease in hydrophobic interactions (Huang et al. 2017). At $\mathrm{pH} 7$, the solution is between the $\mathrm{pK}_{\mathrm{a} 1}(2.30)$ and $\mathrm{pK}_{\mathrm{a} 2}$ (8.43) of SPY, hence the neutral SPY ${ }^{\circ}$ species dominate and act as $\pi$-electron acceptors. These $\pi$-electron acceptors facilitated strong $\pi-\pi$ EDA interactions between SPY and CG700 and this was the predominant adsorption mechanism at $\mathrm{pH} 7$ (Ahmed et al. 2017b).

In contrast, at a $\mathrm{pH}$ of 10 , the anionic $\mathrm{SPY}^{-}$species principally exists in solution and an increase in adsorption was observed (70\% removal after $24 \mathrm{~h}$ ). However, the increase in $\mathrm{SPY}^{-}$removal with increase in $\mathrm{pH}$ is attributed to the formation of negative-charge assisted hydrogen bonds (CAHB). As demonstrated by Teixidó et al. (2011), this mechanism proceeds through the adsorption of negative molecules by the release of $-\mathrm{OH}$ to proton exchange with water $\left(\mathrm{SPY}^{-}+\mathrm{H}_{2} \mathrm{O}\right.$ $\rightarrow \mathrm{SPY}^{\circ}+\mathrm{OH}^{-}$), followed by the formation of exceptionally strong $\mathrm{H}$-bonds between the neutral molecules and the carboxylate functional group present on the CG700 biochar surface (e.g., $\left[\mathrm{RSO}_{2} \mathrm{~N}\left(\mathrm{R}^{\prime}\right) \text {...H.... } \mathrm{O}_{2} \mathrm{C} \text {-surf] }\right]^{-}$). Zheng et al. (2013) reported similar results from the adsorption of sulfamethoxazole (a member of the sulfonamide family with similar properties to SPY) using biochar, where removal still occurred at alkaline $\mathrm{pH}$ due to the formation of CAHB.

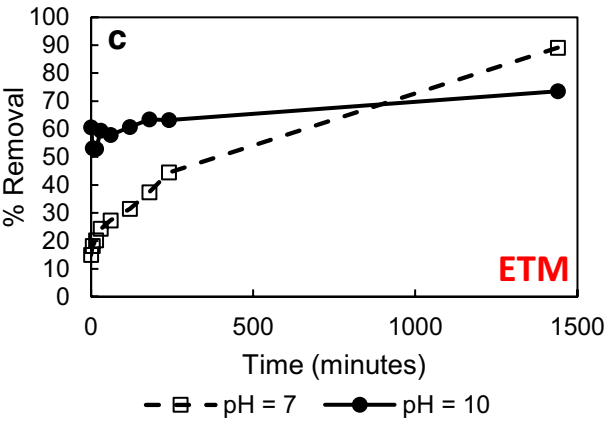

The effect of $\mathrm{pH}$ on the adsorption of DCT and ETM is shown in Fig. 7b, c, respectively. There were no consistent and pronounced differences between the removal of DCT and ETM using CG700 at pH 7 and at pH 10. DCT and ETM are negatively charged at $\mathrm{pH} 7$ and the proportion of negatively charged species increases as the $\mathrm{pH}$ rises. Likewise, CG700 surface becomes increasingly more negative as the $\mathrm{pH}$ becomes more alkaline. Thus, electrostatic repulsion between negatively charged DCT and ETM and the biochar should be reduced at $\mathrm{pH} 7$ relative to $\mathrm{pH} 10$. However, $\pi-\pi$ electron donor acceptor interactions between the $\pi$-electrons of the pharmaceuticals and the $\pi$-electrons in the aromatic ring of the CG700 exists throughout the entire $\mathrm{pH}$ range. Similarly, diffusion, hydrogen bonding and hydrophobic

Table 5 Kinetic parameters of pseudo-second-order models for the adsorption of SPY, DCT and ETM at pH 7 and 10 using CG700 biochar

\begin{tabular}{llllll}
\hline \multirow{2}{*}{ EC } & $\begin{array}{l}q_{\mathrm{e}(\mathrm{exp})} \\
\left(\mathrm{mg} \mathrm{g}^{-1}\right)\end{array}$ & \multicolumn{2}{l}{ Pseudo-second-order kinetic model } \\
\cline { 4 - 6 } & & $\begin{array}{l}k_{2} \\
\left(\mathrm{~g} \mathrm{mg}^{-1} \mathrm{~h}^{-1}\right)\end{array}$ & $\begin{array}{l}q_{\mathrm{e}(\mathrm{cal})} \\
\left(\mathrm{mg} \mathrm{g}^{-1}\right)\end{array}$ & $R^{2}$ \\
\hline $\mathrm{pH} \mathrm{7}$ & SPY & 0.866 & 0.693 & 0.800 & 0.964 \\
& DCT & 1.902 & 1.437 & 1.925 & 0.998 \\
& ETM & 1.752 & 0.249 & 1.851 & 0.949 \\
$\mathrm{pH} \mathrm{10}$ & SPY & 0.785 & 3.176 & 0.766 & 0.997 \\
& DCT & 2.086 & 2.115 & 2.143 & 0.999 \\
& ETM & 1.923 & 2.034 & 1.934 & 0.991 \\
\hline
\end{tabular}


interaction between the biochar and the pharmaceutical are still dominant mechanisms and this results in the similar equilibrium adsorption amount after $24 \mathrm{~h}$ even at different $\mathrm{pH}$ conditions.

\subsection{Kinetics of adsorption at different pH}

The kinetics for the adsorption of the pharmaceuticals onto CG700 biochar was evaluated at $\mathrm{pH} 7$ and 10 and the parameters are shown in Table 5. The experimental data were fitted to the PSO model and high correlation coefficients were observed $\left(R^{2}>0.8\right)$ with excellent linearity. Additionally, the calculated and experimental $q_{e}$ values were similar for both $\mathrm{pH}$ conditions. The excellent fit of the data to the PSO models indicates chemisorption may be the rate limiting step at different $\mathrm{pH}$ values, where electrons sharing through hydrogen bonding, hydrophobic interactions and $\pi-\pi$ EDA interactions occur by valence forces between the pharmaceuticals and CG700 biochar (Qiu et al. 2009). Moreover, it was seen that the PSO rate constant $k_{2}$ is lower at $\mathrm{pH} 7$ than at $\mathrm{pH} 10$ for SPY, DCT and ETM indicating that adsorption at $\mathrm{pH} 7$ required a higher amount of biochar than at $\mathrm{pH} 10$ to achieve the same adsorption efficiency (Ferreira et al. 2015).

\section{Conclusion}

Biochars produced from the pyrolysis of cotton gin waste and guayule bagasse exhibited significant capacity to remove pharmaceuticals from aqueous solution. Removal is a strong function of the solution $\mathrm{pH}$ and the mechanisms involved are hydrophobic interactions, hydrogen bonding and $\pi-\pi$ electron donor acceptor interactions. Adsorption data fit the PSO model, indicating that adsorption was dominated by chemisorption through electron sharing or transfer. These findings demonstrate the potential for biochar to serve as a low-cost additional treatment for reducing pharmaceuticals in treated wastewater prior to beneficial reuse in a wastewater irrigation system. The surface properties of biochar can vary depending on the biochar feedstock, with some functional groups more effective at reducing some pharmaceuticals compared to others. Given that most pharmaceuticals are weak acids or bases that are moderately hydrophobic (log $\left.\mathrm{K}_{\mathrm{ow}} \sim 0-4\right)$, biochar materials that have intermediate degrees of hydrophobicity will likely be most effective in enhancing the removal of pharmaceuticals commonly found in wastewater effluent.

Acknowledgements Support of M. C. Ndoun through a USDA-ARS Cooperative Agreement is gratefully acknowledged. H. A. Elliott, H. E. Preisendanz (formerly, Gall) and J. E. Watson are supported, in part, by the USDA National Institute of Food and Agriculture Federal Appropriations under Project PEN04574 and Accession number 1004448. Mention of trade names or commercial products in this publication is solely for the purpose of providing specific information and does not imply recommendation or endorsement by The Pennsylvania State University or the USDA. Any opinions, findings, and conclusions or recommendations expressed in this publication are those of the authors and do not necessarily reflect the views of The Pennsylvania State University or the USDA.

Open Access This article is licensed under a Creative Commons Attribution 4.0 International License, which permits use, sharing, adaptation, distribution and reproduction in any medium or format, as long as you give appropriate credit to the original author(s) and the source, provide a link to the Creative Commons licence, and indicate if changes were made. The images or other third party material in this article are included in the article's Creative Commons licence, unless indicated otherwise in a credit line to the material. If material is not included in the article's Creative Commons licence and your intended use is not permitted by statutory regulation or exceeds the permitted use, you will need to obtain permission directly from the copyright holder. To view a copy of this licence, visit http://creativecommons.org/licenses/by/4.0/.

\section{References}

Ahmed MB, Zhou JL, Ngo HH, Guo W, Johir MAH, Sornalingam K (2017a) Single and competitive sorption properties and mechanism of functionalized biochar for removing sulfonamide antibiotics from water. Chem Eng J 311:348-358

Ahmed MB, Zhou JL, Ngo HH, Guo W, Johir MAH, Belhaj D (2017b) Competitive sorption affinity of sulfonamides and chloramphenicol antibiotics toward functionalized biochar for water and wastewater treatment. Biores Technol 238:306-312

Angin D (2013) Effect of pyrolysis temperature and heating rate on biochar obtained from pyrolysis of safflower seed press cake. Bioresour Technol 128:593-597

Bartha B, Huber C, Harpaintner R, Schröder P (2010) Effects of acetaminophen in Brassica juncea L. Czern.: investigation of uptake, translocation, detoxification, and the induced defense pathways. Environ Sci Pollut Res 17:1553-1562

Batt AL, Bruce IB, Aga DS (2006) Evaluating the vulnerability of surface waters to antibiotic contamination from varying wastewater treatment plant discharges. Environ Pollut 142:295-302

Belhaj D, Baccar R, Jaabiri I, Bouzid J, Kallel M, Ayadi H, Zhou JL (2015) Fate of selected estrogenic hormones in an urban sewage treatment plant in Tunisia (North Africa). Sci Total Environ 505:154-160

Bolster, C.H. (2019). Role of sand size on bacterial retention in biochar-amended sand filters. Biochar, 2524-7867, 1-11

Brown S, Rowley G, Pearson JT (1998) Surface treatment of the hydrophobic drug danazol to improve drug dissolution. Int J Pharm 165:227-237

Cao X, Harris W (2010) Properties of dairy-manure-derived biochar pertinent to its potential use in remediation. Bioresour Technol 101:5222-5228

Chung HK, Kim WH, Park J, Cho J, Jeong TY, Park PK (2015) Application of Langmuir and Freundlich isotherms to predict adsorbate removal efficiency or required amount of adsorbent. J Indus Eng Chem 28:241-246

Daughton CG (2004) Non-regulated water contaminants: Emerging research. Environ Impact Assess Rev 24:711-732

de Caprariis B, De Filippis P, Hernandez AD, Petrucci E, Petrullo A, Scarsella M, Turchi M (2017) Pyrolysis wastewater treatment by adsorption on biochars produced by poplar biomass. J Environ Manag 197:231-238 
Department of Soil and Water Sciences (DSWS) (2011) Reclaimed water used in the landscape: What's in reclaimed water and where does it go? https://edis.ifas.ufl.edu/ss542

Ding W, Dong X, Ime IM, Gao B, Ma LQ (2014) Pyrolytic temperatures impact lead sorption mechanisms by bagasse biochars. Chemosphere 105:68-74

Essandoh M, Kunwar B, Pittman CU Jr, Mohan D, Mlsna T (2015) Sorptive removal of salicylic acid and ibuprofen from aqueous solutions using pine wood fast pyrolysis biochar. Chem Eng J 265:219-227

Fenet H, Prommer H, Mahjou O, Li Z, Hillaire-Buys D, Casellas C, Gomez E (2012) Carbamazepine, carbamazepine epoxide and dihydroxycarbamazepine sorption to soil and occurrence in a wastewater reuse site in Tunisia. Chemosphere 88:49-54

Ferreira RC, Couto Junior OM, Carvalho KQ, Arroyo PA, Barros MA (2015) Effect of Solution $\mathrm{pH}$ on the Removal of Paracetamol by Activated Carbon of Dende Coconut Mesocarp. Chem Biochem Eng Q J 29(1):47-53

Foo KY, Hameed BH (2010) Insights into the modeling of adsorption isotherm systems. Chem Eng J 156:2-10

Fu P, Yi W, Bai X, Li Z, Hu S, Xiang J (2011) Effect of temperature on gas composition and char structural features of pyrolyzed agricultural residues. Bioresour Technol 102:8211-8219

Geudidi H, Reinert L, Soneda Y, Bellakhal N, Duclaux L (2017) Adsorption of ibuprofen from aqueous solution on chemically surface-modified activated carbon cloths. Arab J Chem 10:S3584-S3594

Gibson R, Durán-Álvarez J, León EK, Chávez A, Jiménez CB (2010) Accumulation and leaching potential of some pharmaceuticals and potential endocrine disruptors in soils irrigated with wastewater in the Tula Valley, Mexico. Chemosphere 81:1437-1445

Gong R, Zhu S, Zhang D, Chen J, Ni S, Guan R (2008) Adsorption behavior of cationic dyes on citric acid esterifying wheat straw: kinetic and thermodynamic profile. Desalination 230:220-228

Goswami R, Deb P, Thakur R, Sarma KP, Basumallick A (2011) Removal of As(III) from aqueous solution using functionalized ultrafine iron oxide nanoparticles. Sep Sci Technol 46:1017-1022

Goswami R, Shim J, Deka S, Kumari D, Kataki R, Kumar M (2016) Characterization of cadmium removal from aqueous solution by biochar produced from Ipomoea fistulosa at different pyrolytic temperatures. Ecol Eng 97:444-445

Gros M, Petrovic M, Ginebreda A, Barcelo D (2010) Removal of pharmaceuticals during wastewater treatment and environmental risk assessment using hazard indexes. Environ Int 36:15-26

Ho YS (2006) Second-order kinetic model for the sorption of cadmium onto tree fern: a comparison of linear and non-linear methods. Water Res 40:119-125

Houtman CJ (2010) Emerging contaminants in surface water and their relevance for the production of drinking water in Europe. J Integr Environ Sci 7(4):271-295

Huang D, Wang X, Zhang C, Zeng G, Peng Z, Zhou J, Cheng M, Wang $\mathrm{R}, \mathrm{Hu}$ Z, Qin X (2017) Sorptive removal of ionizable antibiotic sulfamethazine from aqueous solution by graphene oxide-coated biochar nanocomposites: influencing factors and mechanism. Chemosphere 186:414-421

Inyang M, Gao B, Pullammanappallil P, Ding W, Zimmerman AR (2010) Biochar from anaerobically digested sugarcane bagasse. Bioresour Technol 101:8868-8872

Ji LL, Chen W, Zheng SR, Xu ZY, Zhu DQ (2009) Adsorption of sulfonamide antibiotics to multiwalled carbon nanotubes. Langmuir 25:11608-11613

Johnson PR, Sun N, Elimelech M (1996) Colloid transport in geochemically heterogeneous porous media: modeling and measurements. Environ Sci Technol 30(11):3284-3293

Kinney CA, Furlong ET, Werner SL, Cahill JD (2006) Presence and distribution of wastewater-derived pharmaceuticals in soils irrigated with reclaimed water. Environ Toxicol Chem 25(2):317-326

Kinney TJ, Masiello CA, Dugan B, Hockaday WC, Dean MR, Zygourakis K, Barnes RT (2012) Hydrologic properties of biochars produced at different temperatures. Biomass Bioenerg 41:34-43

Kloss S, Zehetner F, Dellantonio A, Hamid R, Ottner F, Liedtke V, Schwanninger M, Gerzabek MH, Soja G (2012) Characterization of slow pyrolysis biochars: effects of feedstocks and pyrolysis temperature on biochar properties. J Environ Qual 41:990-1000

Kolpin DW, Furlong ET, Meyer MT, Thurman EM, Zaugg SD, Barber LB, Buxton HT (2002) Pharmaceuticals, hormones, and other organic wastewater contaminants in U.S. streams, 1999-2000: a national reconnaissance. Environ Sci Technol 36:1202-1211

Krishnan KA, Haridas A (2008) Removal of phosphate from aqueous solutions and sewage using natural and surface modified coir pith. J Hazard Mater 152(2):527-535

Kupryianchyk D, Hale S, Zimmerman AR, Harvey O, Rutherford D, Abiven S, Knicker H, Schmidt H-P, Rumpel C, Cornelissen G (2016) Sorption of hydrophobic organic compounds to a diverse suite of carbonaceous materials with emphasis on biochar. Chemosphere 144:879-887

Lata H, Garg VK, Gupta RK (2007) Removal of a basic dye from aqueous solution by adsorption using Parthenium hysterophorus: an agricultural waste. Dye Pigment 74:653-658

Lehmann, J., Joseph, S. (2009). Biochar for environmental management: science and technology. Earthscan Press, ISBN 978-1-84407-658-1.

Liu P, Liu WJ, Jiang H, Chen JJ, Li WW, Yu HQ (2012) Modification of biochar derived from fast pyrolysis of biomass and its application in removal of tetracycline from aqueous solution. Biores Technol 121:235-240

Maglinao AL Jr, Capareda SC, Nam H (2015) Fluidized bed gasification of high tonnage sorghum, cotton gin trash and beef cattle manure: evaluation of synthesis gas production. Energy Convers Manag 105:578-587

McFarland JW, Berger CM, Froshauer SA, Hayashi SF, Hecker SJ, Jaynes BH, Jefson MR, Kamicker BJ, Lipinski CA, Lundy KM, Reese CP, Vu CB (1997) Quantitative structure-activity relationships among macrolide antibacterial agents: in vitro and in vivo potency against Pasteurella multocida. J Med Chem 40:1340-1346

Mohanty SK, Boehm AB (2014) Escherichia coli removal in biocharaugmented biofilter:effect of infiltration rate, initial bacterial concentration, biochar particle size, and presence of compost. Environ Sci Technol 48:11535-11542

Mondal S, Bobde K, Aikat K, Halder G (2016) Biosorptive uptake of ibuprofen by steam activated biochar derived from mung bean husk: equilibrium, kinetics, thermodynamics, modeling and ecotoxicological studies. J Environ Manage 182:581-594

Mostafapour KF, Dashtizade M, Balarak D (2019) Adsorption thermodynamics, kinetics and mechanism for the adsorption of erythromycin onto multi-walled carbon nanotubes. J Pharma Res Intl 24(6): $1-11$

National Center for Biotechnology Information. PubChem Compound Database, U.S. National Library of Medicine, pubchem.ncbi.nlm. nih.gov

Novak JM, Cantrell KB, Watts DW (2012) Compositional and thermal evaluation of lignocellulosic and poultry litter chars via high and low temperature pyrolysis. Bioener Res.,1939-1234.

Pal A, Gin KY, Lin AY, Reinhard M (2010) Impacts of emerging organic contaminants on freshwater resources: review of recent occurrences, sources, fate and effects. Sci Total Environ 408(24):6062-6069

Qiu H, Lv L, Pan B-C, Zhang Q-J, Zhang W-M, Zhang Q-X (2009) Critical review in adsorption kinetic models. J Zheijang Univ Sci A $10: 716-724$ 
Reddy KR, Xie T, Dastgheibi S (2014) Evaluation of biochar as a potential filter media for the removal of mixed contaminants from urban storm water runoff. J Environ Eng 140:04014043

Reguyal F, Sarmah AK, Gao W (2017) Synthesis of magnetic biochar from pine sawdust via oxidative hydrolysis of $\mathrm{FeCl} 2$ for the removal sulfamethoxazole from aqueous solution. J Hazard Mater 321:868-878

Sabaini SP, Boateng AA, Schaffer M, Mullen CA, Elkasabi Y, McMahan CM, Nelson M (2018) Techno-economic analysis of guayule (Parthenium argentatum) pyrolysis biorefining: production of biofuels from guayule bagasse via tail-gas reactive pyrolysis. Ind Crops Prod 112:82-89

Sumalinog DAG, Capareda SC, de Luna MDG (2018) Evaluation of the effectiveness and mechanisms of acetaminophen and methylene blue dye adsorption on activated biochar derived from municipal solid wastes. J Environ Manag 210:255-262

Sui Q, Huang J, Deng S, Chen W, Yu G (2011) Seasonal variation in the occurrence and removal of pharmaceuticals and personal care products in different biological wastewater treatment processes. Environ Sci Technol 45:3341-3348

Sun Y, Zhu J-W, Chen K, Xu J (2009) Modelling erythromycin adsorption to the macroporous resin sepabead SP825. Chem Eng Com 196(8):906-916

Taheran M, Naghdi M, Brar SK, Knystautas EJ, Verma M, Ramirez AA, Valero JR (2016) Adsorption study of environmentally relevant concentrations of chlortetracycline on pinewood biochar. Sci Total Environ 571:772-777

Teixidó M, Pignatello JJ, Beltrán JL, Granados M, Peccia J (2011) Speciation of the ionizable antibiotic sulfamethazine on black carbon (biochar). Environ Sci Technol 45:10020-10027
Uchimiya M, Klasson KT, Wartelle LH, Lima IM, Chanel AF (2011) Influence of pyrolysis temperature on biochar property and function as a heavy metal sorbent in soil. J Agr Food Chem 59:2501-2510

US Geological Survey, (2015). Emerging Contaminants in the Environment. https://toxics.usgs.gov/regional/emc/

Wang L, Yang L, Li Y, Zhang Y, Ma X, Ye Z (2010) Study on adsorption mechanism of $\mathrm{Pb}(\mathrm{II})$ and $\mathrm{Cu}(\mathrm{II})$ in aqueous solution using PS-EDTA resin. Chem Eng J 163:364-372

Wu SH, Pendleton P (2001) Adsorption of anionic surfactant by activated carbon: effect of surface chemistry, ionic strength, and hydrophobicity. J Colloid Interface Sci 243:306-315

Xie M, Chen W, Xu Z, Zheng S, Zhu D (2014) Adsorption of sulfonamides to demineralized pine wood biochars prepared under different thermochemical conditions. Environ Pollut 186:187-194

Yao Y, Zhang Y, Gao B, Chen R, Wu F (2017) Removal of sulfamethoxazole (SMX) and sulfapyridine (SPY) from aqueous solutions by biochars derived from anaerobically digested bagasse. Environ Sci Pollut Res 25:25659-25667

Yanyan L, Kurniawan TA, Zhu M, Ouyang T, Avtar R, Dzarfan Othman MH, Albadarin AB (2018) Removal of acetaminophen from synthetic wastewater in a fixed-bed column adsorption using lowcost coconut shell waste pretreated with $\mathrm{NaOH}, \mathrm{HNO}_{3}$, ozone, and/or chitosan. J Environ Mang 226:365-376

Zheng H, Wang Z, Zhao J, Herbert S, Xing B (2013) Sorption of antibiotic sulfamethoxazole varies with biochars produced at different temperatures. Environ Pollut 181:60-67

Zheng W, Guo M, Chow T, Bennett DN, Rajagopalan N (2010) Sorption properties of green waste biochar for two triazine pesticides. J Hazard Mater 181:121-126 